\title{
Tardive Dyskinesia: Barriers to the Professional Recognition of an Iatrogenic Disease*
}

\author{
PHIL BROWN \\ Brown University and Harvard Medical School \\ STEVEN C. FUNK \\ University of Kansas
}

Journal of Health and Social Behavior 1986, Vol. 27 (June):116-132

\begin{abstract}
Tardive dyskinesia (TD), once regarded by psychiatrists as a rare occurrence, is currently recognized as the most pervasive side effect (other than sedation) of antipsychotic medication. Early reports linking antipsychotic drugs to TD met with considerable criticism. Mounting evidence concerning high prevalence of the disorder among psychiatric patients has led to a general acceptance of the syndrome as drug induced, but this recognition has coexisted with elements of resistance. This paper assesses the social epidemiology of TD, the process by which $T D$ was generally recognized as a major iatrogenic illness, and coexisting resistance to such recognition. The resistance and incomplete recognition are then discussed in light of structural elements of professional dominance. The history of the TD phenomenon informs us that the discovery of illness is a broad sociomedical question rather than merely a biomedical one.
\end{abstract}

\section{INTRODUCTION}

Tardive dyskinesia (TD), once regarded by psychiatrists as a rare syndrome, is currently recognized as the second most pervasive side effect (following sedation) of antipsychotic drugs. This often irreversible disorder of the central nervous system results in a variety of involuntary movements, particularly of the tońgue, lips, and jaw (Jeste and Wyatt 1982b). The recognition of TD as a side effect has been a slow and uneven process, involving psychiatric resistance alongside aspects of open scientific investigation. The process leading to the present acceptance of TD as drug induced has been fraught with controversy regarding the

*Direct all correspondence to: Phil Brown, Department of Sociology, Brown University, Providence, RI 02912.

Presented at the Annual Meeting of the American Sociological Association, Washington, D.C., August 30, 1985. The authors would like to thank Renee Anspach, Peter R. Breggin, Edward Brown, Peter Conrad, George E. Crane, Ronnie Littenberg, Catherine Kohler Riessman, and two anonymous reviewers for valuable comments on this paper. Discussions with C. Thomas Gualtieri and Richard J. Wyatt were also helpful. etiology, prevalence, reversibility, and treatment of the syndrome. TD has come to hold an important place in the controversy over whether to inform patients of the risks of antipsychotic drugs.

Given the serious, debilitating nature of TD and its irreversibility in many cases, one may ask why the recognition of TD took so long. A corollary question is whether this recognition has altered psychiatric practice in such a way as to reduce the risk factors. In exploring these issues, a medical-sociological perspective requires that we look not only at medical factors in recognition and resolution of TD, but also at social factors.

The thesis of this paper is that the prevalence of tardive dyskinesia and the incomplete way in which it has been dealt with are reflections of psychiatry's effort to become more "medical." Over the past two decades, the long dominance of psychoanalysis has been challenged by biological approaches to psychiatry, which promised to lift the status of psychiatry in the medical world. Psychopharmacology has been central to this biopsychiatric revolution in psychiatric thinking (Klerman 1982; Light 1980). The successful application of psycho- 
tropic drugs led doctors to think that psychotherapy would be more feasible for previously unreachable patients. Drug treatment provided the first major technique for symptomatic relief of these patients. Psychotropic drugs diminished or halted symptoms such as paranoid delusions, auditory hallucinations, and thought disorder. Because these drugs often made physical restraint unnecessary, they were at first regarded as a more humane approach. It also held promise for making the long-criticized public mental hospitals more humane.

It may seem tempting to consider biopsychiatric tendencies as manifestations of some components of the classic conception of professional development: emphasis on the development of a knowledge base, guidance by principles of scientific rationality, service ethic rather than self-interest, and positive selfregulation (Goode 1960; Parsons 1959). One could then argue that the strain of developing a more scientific base led to an uncritical embracing of the new drug therapy, which in turn led to the current situation of therapeutic gain mixed with considerable hazard.

There is some validity to viewing psychiatric advocacy of psychopharmacology as indicative of a classic model of professional development. Yet such a perspective downplays some important facets of the situation. As Freidson's (1970) conflict perspective argues, doctors often quite consciously engage in practices which further their professional advancement. They lack a pure collectivityorientation, and in fact hold elitist and authoritarian opinions toward their patients. Further, the structural limitations of the larger service delivery system impinge on what client service orientation the psychiatrists might have.

Psychiatrists did not embrace pharmacology solely to serve their patients better, though such motivation clearly was important. Professional self-interest was a crucial element as well, inasmuch as psychiatrists sought more acceptance by their medical colleagues. General adherence to a strict medical model leads practitioners to think in terms of symptom relief, without sufficient regard for the larger phenomenon of the patient's total experience of illness or of the treatment.

Research in the traditions of social con- structivism (Mishler et al. 1981; Zola 1983) and labeling theory (Scheff 1975) illuminates another issue: the tendency to discount complaints by "incompetents." To the extent that severely disturbed persons are viewed in the role of deviants, they lose credibility and autonomy. Thus, their experience of illness and side effects are of too little concern to providers. The practical habits of labeling and treating take precedence over research, analysis, and critical reflection. This precedence of practice is particularly evident in light of the major dilemma posed by neuroleptic drugs: These drugs often provide relief for the most devastating symptoms of psychosis, but produce severe side effects. Yet the drive to treat symptoms predominates, leading most psychiatrists to slight this dilemma (Diamond 1985; Estroff 1981).

There are, then, competing models of professional behavior involved here. A drive for greater scientific knowledge and better care exists, but it coexists with self-interest, elitism, and a failure to balance risks and benefits. As a result, TD has been inappropriately handled in terms of recognition of the disease and in methods of dealing with it (e.g. informed consent, reduced dosages, rigorous monitoring) (Crane 1977).

Using TD as a case history which can be generalized to other areas, this paper examines how these competing approaches to professional practice affect psychiatric treatment. In order to explore this topic, this paper will first present the social epidemiology of tardive dyskinesia. Next there will be a section on the coexisting recognition and resistance to recognition of TD. Finally there will be a discussion of those elements of medical psychiatric practice and its world view which place obstacles in the path of recognition and of adequate prevention and treatment of TD.

\section{SOCIAL EPIDEMIOLOGY OF TARDIVE DYSKINESIA}

The first phenothiazine derivative, chlorpromazine, was synthesized in France in 1950 and introduced into the United States in 1952. Phenothiazines, commonly used at that time as an insecticide and as treatment for parasitic intestinal worms, came to be employed as a 
treatment for Parkinson's disease, surgical shock, motion sickness, nausea, vomiting, itching, and as a general sedative and as a potentiator for analgesics and anaesthesia (Swazey 1974, pp. 49-54, 77-81, 139-141). Ultimately phenothiazine derivatives were employed most importantly in the treatment of acute psychotic symptoms associated with schizophrenia.

At the time of its introduction into the U.S., chlorpromazine (brand name, Thorazine) had been tested on only 104 psychiatric patients in this country (Swazey 1974, p. 195). Furthermore, even though there continued to be a general lack of testing for safety and efficacy (Glick and Margolis 1962), phenothiazine use proliferated very rapidly. In 1954 the American pharmaceutical firm of Smith, Kline, and French (SKF) formed a special task force of 50 detail men to market Thorazine, at a time when its total national sales force was only 300 . SKF and the French originator, Rhone-Poulenc, also funded many hospital research programs and professional conferences. Within eight months of its marketing, Thorazine was given to about two million patients (Swazey 1974, pp. 160, 202-208).

\section{Symptomatology}

Within five years after the introduction of phenothiazines it was noted that they produced neurological side effects, including dystonias (involuntary muscle spasms), akinesia (immobility), akathisia (severe restlessness), and Parkinsonism (tremor, shuffling gait). These side effects have a relatively rapid onset of symptoms following initiation of drug treatment (typically within the first two months), and are treatable. Because of this, it was widely believed in the 1960s that these and other neurotoxic effects of neuroleptics ${ }^{1}$ were reversible through drug reduction or disconinuation (Schmidt and Jarcho 1966).

The clinical manifestations of TD are similar in many ways to the syndromes noted above. The bucco-lingual-masticatory (BLM) triad comprises the most frequent and notable of TD symptoms, including sucking and smacking motions of the lips, lateral jaw movements, and often rhythmical, thrusting, or "fly-catching" movements of the tongue (Schiele et al. 1973).
Other involuntary movements include movements of the trunk and abnormal gait and may involve nearly all muscles of the body (Crane and Paulson 1967; Turek et al. 1972). The distinguishing features of TD lie mainly in time of onset and in persistence (Crane and Paulson 1967). While TD may occur following only weeks of neuroleptic use, it may become apparent only after years of treatment (Fann et al. 1972). Symptoms of TD often become evident only after medication is withdrawn. Unlike the other disorders, TD appears in many cases to persist for many years or to be irreversible.

\section{Case Finding}

Schonecker first described a syndrome associated with phenothiazine use in 1957; three years later, Uhrbrand and Faurbye termed this syndrome tardive dyskinesia (Gibson 1978). According to Jeste and Wyatt (1981), the reported prevalence of TD has increased markedly since then:

The overall weighted mean prevalence of tardive dyskinesia among inpatients was $13.6 \%$ until 1970 (based on 19 studies) and has jumped to $23.3 \%$ since 1971 (based on 17 studies). Moreover, 13 of the last 17 studies individually found a prevalence exceeding $22 \%$. The weighted mean prevalence in the 11 studies published during the past five years (1976 through 1980) is $25.7 \%$.

The increase in reported prevalence of TD for the years $1960-1980$ is shown graphically in Figure 1, which presents weighted mean prevalence of TD at five-year intervals for studies published in that period.

This increase over time is generally considered to be a true increase, due to the fact that (1) more patients became neuroleptic users, (2) more patients had longer at-risk periods, and (3) more recent neuroleptics have tended to be higher-dose drugs (Kane and Smith 1982). Yet it is reasonable to ask if increased reporting of TD also contributes to the increased prevalence. Two major obstacles to the recognition of TD were that clinicians were not trained to detect TD, or else were convinced that TD symptoms were manifestations of other conditions.

With this epidemiological data in hand, it is 
FIGURE 1. Prevalence of Tardive Dyskinesia (Weighted Mean \%) Among Inpatients Treated with Neuroleptics (in 5-Year Intervals, 1960-1980). SOURCE: Jeste and Wyatt (1981).

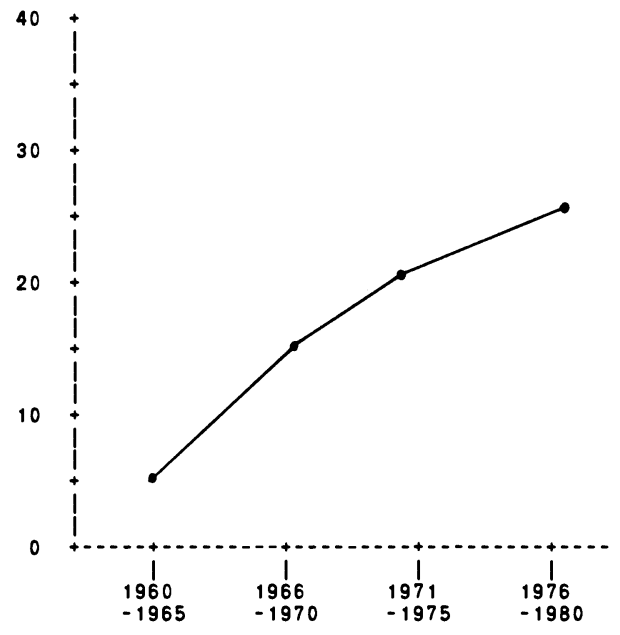

appropriate to turn to the process by which TD was recognized.

\section{RECOGNITION AND RESISTANCE}

\section{Methodological Problems}

Much of the initial difficulty in professional recognition of TD has been lack of agreement on the existence, extent, and characteristics of the illness. As will be shown, this has been due in part to methodological problems; some of these problems involve psychotropic drug research in general, while others are specific to the detection and measurement of TD.

However, some of the methodological issues concern not merely errors or failures, but decisions to choose methods and data that minimize the problems. For example, reported prevalence for a group of inpatients varied from $6.9 \%$ to $62.2 \%$, depending on the stringency of the criteria chosen to define tardive dyskinesia (Smith et al. 1979). This variation is depicted in Table 1 . Of the 36 studies meeting Jeste and Wyatt's (1981) minimal requirements for review, only seven mentioned the severity of the symptoms used to establish the diagnosis. The choice of a high criterion level ignores lower levels of TD symptoms and leads to low prevalence rates, which can then be used to minimize the gravity of the TD problems.

Though use of the double-blind procedure is crucial in drug testing, Jeste and Wyatt (1982a) note that only $23 \%$ of published treatment studies of TD employed double-blind conditions. The shortcoming has pronounced effects on outcomes: The mean number of patients showing at least "moderate" improvement was $59.7 \%$ for patients in the 23 single-blind studies, compared to only $37.5 \%$ in 12 doubleblind studies (Glick and Margolis 1962). This demonstrates that the expectations of experimenters significantly biased results by overstating the effectiveness of the drug treatment and inflating estimates of the effectiveness of various drugs in counteracting the symptoms of TD.

Aside from such biasing factors, there are other methodological problems. Differential diagnosis of TD is difficult for a number of reasons: There is no clinical or laboratory test that can establish or rule out the syndrome; gradual onset makes it hard to date onset; patients are often unaware of the condition; severity and symptom location fluctuate over time; non-TD movements coexist with TD; symptoms may be caused by nonneuroleptic drugs and other conditions; neuroleptics often suppress TD; and there is no clear dose-effect relationship (Jeste and Wyatt 1982b, pp. 58-59). A determination of the effects of specific neuroleptics is often made more difficult in retrospective studies due to changes in dosage schedules that often occur over time, and the frequent use of multiple neuroleptics, or "cocktails." Few patients have been observed

TABLE 1. Prevalence of TD as a Function of Criterion Level $(\%)^{1}$

\begin{tabular}{lcc}
\hline \hline $\begin{array}{l}\text { Criterion } \\
\text { Level }\end{array}$ & $\begin{array}{c}\text { Inpatients } \\
(N=293)\end{array}$ & $\begin{array}{c}\text { Outpatients } \\
(N=213)\end{array}$ \\
\hline 2.0 & 62.2 & 72.3 \\
2.5 & 45.9 & 40.9 \\
3.0 & 30.2 & 23.7 \\
3.5 & 13.8 & 8.6 \\
4.0 & 6.9 & 2.4 \\
\hline
\end{tabular}

${ }^{1}$ Criterion level is for the Abnormal Involuntary Movement Scale (AIMS). The higher the criterion level, the greater the severity of symptoms needed to indicate presence of tardive dyskinesia. SOURCE: Smith et al. 1979. 
throughout the course of TD (Quitkin et al. 1977). A further obstacle to accurate prevalence reporting is that patients may consciously inhibit or limit their abnormal movements, particularly when aware of being observed (Fann et al. 1977). Such diagnostic problems, however, are not sufficient reason for professional resistance.

It may be argued that methodological problems in neuroleptic research are no different from those facing all psychiatric drug research. Indeed, an evaluation of antidepressant drug research (Prien and Levine 1984) suggests that this is so. However, a number of major researchers in the TD field (Gardos and Cole 1980; Jeste and Wyatt 1982b; Sprague et al. 1984) maintain that TD does pose a more difficult research problem than other drug-related issues, for reasons mentioned in the preceding discussion. Also, despite attempts to devise and implement standardized rating scales of severity of TD, such scales have arbitrary cut points (Gardos and Cole 1980) and have not been subject to the scrutiny usually seen in other rating scales in terms of reliability, validity, and stability (Sprague et al. 1984).

A more general response to this argument of a commonality of problems can be made: Even if such a commonality exists, the fact remains that TD is a major public health hazard which has become more serious partly as a result of poor scientific approaches. Therefore, it is necessary to work backward to locate various reasons for this phenomenon. Were antidepressants, lithium, or antianxiety drugs to exhibit such disturbing iatrogenic effects, such an approach would be similarly justified.

In addition to methodological problems, there are related conceptual issues. For example, assertions that TD was not a phenothiazine side effect were widespread in the literature published before the early 1970s (e.g., Curran 1973; Schmidt and Jarcho 1966). Symptoms similar to those of TD may occur spontaneously, especially among older and chronically institutionalized patients, though at a very low frequency (Jeste and Wyatt 1981).

Psychiatrists often held that symptoms were due to other pathological conditions. For example, many early reports cited the presence of brain damage as evidence for dismissing the existence of persistent TD (e.g., Kline 1968). Some believed that abnormal tongue move- ments attributed to TD might be efforts to moisten the lips and tongue in order to counteract the dryness of mouth often associated with phenothiazine use (Kline 1968). Curran (1973, p. 408) suggested that what was perceived as TD may have been confused with a process in which "the behavioral repertoire of such patients (chronically institutionalized, often difficult ones) becomes more impoverished the more they are hospitalized."

These methodological and conceptual problems may have made it hard for psychiatrists to recognize TD in the early period. But it is precisely these problems of method which allow drug treatments to proliferate without sufficient precautions. The effect of poor research methods was to mask the problem in part. More importantly, the slow development of the knowledge base can only account for early ignorance. Subsequent failure to accept evidence of TD or to take adequate measures must be seen as stemming from a desire to protect the pharmacological advances from criticism.

By as early as 1970 , and more clearly by the mid-1970s, there was enough evidence in the literature to warrant the identification of TD as a serious outcome. Also, by that point, much had been published on methodological problems, so that clinicians had the opportunity both to re-evaluate past research, and to engage in more rigorous investigation. In the next section, on gradual recognition, it can be seen that even at a very early period it was possible to see TD as an issue.

\section{Gradual Recognition}

In the late 1960s, George Crane, a psychiatric investigator at the National Institute of Mental Health (NIMH), pursued TD research and attempted to alert his fellow psychiatrists to the extent of the problem. He devised the first screening instrument, studied prevalence in many locations, explored risk factors, examined the physiological components of the disease, and published widely in an effort to spread the word. In Crane's (1980) opinion, sufficient research evidence existed in 1970 to allow for recognition of TD, yet "the majority of psychiatrists either ignored the existence of the problem or made futile efforts to prove that 
these motor abnormalities were clinically insignificant or unrelated to drug therapy."

SKF and other drug firms lobbied extensively in Congress to prevent more stringent regulation (Waldon 1977). However, in reaction to a lawsuit, SKF in 1972 became the first manufacturer to warn of TD in package inserts (Lennard and Bernstein 1974). The next year the American College of Neuropharmacology and the Food and Drug Administration (FDA) co-authored an editorial informing the psychiatric profession of the TD problem (Schiele et al. 1973). The litigation and letter both attest to some early awareness of TD. According to Crane (1974), even this was too late, and the FDA should have taken a more active role in drug regulation. By 1974, there was much evidence of such a crisis, including SKF inserts, FDA and professional bodies' warnings, and a large body of ignored research literature. Yet according to Crane (1974), most psychiatrists ignored or resisted such knowledge:

Psychiatrists and other physicians may be blamed for not being familiar with the medical literature, and for depending too much on promotional material and information of fered by the detail men of drug companies. There is certainly no lack of published material in the field of psychopharmacology.

Crane was something of a maverick crusader, though he was by no means "antipsychiatric." Even though Crane had been an NIMH staff scientist in the 1960s, his work was not well received at first. A leading pharmacologist, Jonathan Cole, responded to Crane's 1974 paper to the New York Academy of Sciences by saying that Crane's prevalence estimates were too high. Cole claimed that only $5 \%$ of the patients at the state hospital where he worked had TD, that many of them had pre-existing brain damage or severe mental retardation, and that none were seriously incapacitated. As to Crane's motivation, Cole (1974) wrote that "he obviously has undertaken the role of Cassandra within psychiatry, foreseeing doom in many aspects of our current scientific and clinical operations." The ad hominem nature of Cole's retort suggests some degree of resistance to recognition.

Crane believed that physicians in general had a hard time accepting any iatrogenic phenomenon. His associate, George Paulson
(1975), wrote: "The common rejoinder in an iatrogenic disorder is to assume that the occurrence is inevitable, or alternatively to assert that the severity of the basic illness justified the iatrogenic measures." Thus, argue these early discoverers, despite a significant amount of evidence by the mid-1970s, there was considerable avoidance to recognizing TD. This avoidance takes both active and passive forms. Active forms involve refutation of the findings of TD critics and/or statements that neuroleptic benefits outweigh TD side effects. Passive forms involve failure to alter treatment practices so as to minimize the incidence of TD. Such behavior need not be seen as consciously malevolent. It may have been due to unchecked optimism in the period of the rise of psychopharmacology, or to a desire to disregard the negative aspects of the new drug technology. Yet it was still avoidance. In terms of what came later in the 1980s-resistance in spite of widespread recognition-it is easier to argue that the mid-1970s' attitudes were motivated by a real desire not to see TD.

Such motivation can be understood as stemming from the desire to defend not only the pharmacological advances but their role in professional development. Additionally, psychiatrists wanted to promote the deinstitutionalization process, for which drugs were a critical prerequisite. Deinstitutionalization provided a paradox, though, since it first required that TD go unrecognized, yet later offered a context for greater recognition.

Although the state hospital inpatient census declined from almost 559,000 in 1955 to less than 138,000 in 1980 (NIMH 1983), what was originally a fresh approach to mental health care came to be regarded by the mid-1970s as a very problematic policy. Deinstitutionalization was blemished by poor follow-up and aftercare, minimal coordination between agencies, inadequate funding, and reliance on drugs to the relative exclusion of other forms of treatment. Emptying the state hospitals and tightening admissions criteria led to massive numbers of severely disturbed persons in nursing homes, boarding homes, welfare hotels, and the streets (Brown 1985). Thus the outcome of deinstitutionalization was not wholly positive. In addition, because the chronically mentally ill were more likely to be in the community rather than hidden away in an institution, there 
was greater public awareness of TD. Chronic patients living outside the hospital had more opportunities to fail to take their medication whether intentionally or unintentionally. This last result of deinstitutionalization contributes to the increase in TD prevalence, since TD often appears only upon drug withdrawal.

These effects of deinstitutionalization were important in calling attention to TD as a public health crisis; this complemented and even spurred advances in research methods and clinical observation. Evidence of a TD epidemic accumulated, as rising prevalence rates made it harder to dismiss the data. TD came to be considered a specific syndrome, although dispute still occurs concerning its distinction from other side effects. TD symptoms are recognized as side effects of antipsychotic drugs, and the condition is generally recognized as persistent in as many as onethird of all cases. The impact of the observed change in prevalence on physicians' attitudes toward TD is illustrated by the views of one of the leading psychopharmacologists in the United States, Nathan Kline, who helped introduce phenothiazines into this country. In 1968 Kline commented on the rarity and insignificance of TD, arguing that its incidence was "negligible" (Kline 1968). This view is very different from that he expressed in 1976, when he noted that tardive dyskinesia occurred frequently enough to be considered "a matter of extreme importance" (Simpson and Kline 1976).

\section{Official Recognition}

Important official recognition occurred in the mid and late 1970s. In 1975, NIMH researchers developed the now widely used AIMS (Abnormal Involuntary Movements Scale) (Gardos and Cole 1980). In 1979 the American Psychiatric Association's Task Force on Tardive Dyskinesia published its final report. The task force guidelines state that psychiatrists should consider long-term indications carefully and use objective measures to ascertain whether the patient is benefitting from medication; alternatives to drug treatment should be sought for neurosis and for mood and character disorders; clinicians should avoid polypharmacy and strive for lower doses, especially in children and elderly patients; families and patients should be advised of risks and benefits; oral rather than written consent should be required; regular examinations should be conducted to check for TD symptoms; clnicians should re-evaluate and document indications and response to medications at least every three to six months; at the earliest sign of TD, psychiatrists should lower dosage, change to a less potent drug, or, ideally, stop medications (Baldessarini et al. 1979 , p. 169). In addition to systematizing knowledge, an effort such as that of the task force is designed to educate psychiatrists and to demonstrate the importance of the issue in the eyes of professional leaders.

\section{Ignorance and Resistance}

Despite this educational intent, the American Psychiatric Association (APA) has not strenuously brought the TD problem to the attention of its membership or to that of government and the public, as gauged by noting official statements and journals' content. For instance, the APA published its report in 1979, yet waited until 1985 to send all members a letter detailing its concerns about TD. Nor have professional leaders examined in print the social factors involved in the TD situation, such as the impact of deinstitutionalization, personal suffering of the patients, and professional and institutional practice styles. This inaction is noticeable when compared to APA action on another major issue, the homeless mentally ill. On that matter, the APA has used press conferences, public pronouncements, and professional workshops to broadcast its perspective; and has addressed social factors such as the housing crisis and cutbacks in social service spending.

In response to pressure from NIMH and the American College of Neuropsychopharmacology, the APA reconvened the task force to deal with the specific issue of educating the members of the psychiatric profession. This action prompted Gualtieri et al. (1985, p. 22) to say that "the 'massive education campaign' recommended by George Crane in 1973 is finally taking shape."

Specialty organizations, such as the APA, are largely unable to make significant changes 
in physicians' practice styles. With the exception of advising against use of certain treatments with primarily harmful effects and doubtful benefits, there is rarely any policy action by medical bodies. But one might expect the APA task force report to urge stronger educational programs and to suggest types of monitoring practices for both private practitioners and institutions. Although the task force was ahead of much of the APA's membership in recognizing the extent of TD, it could have done more. For example, it could have addressed the delay in recognition of the problem-a recognition which was empirically possible over a decade before the APA report, if we accept the widely published work of Crane at that time and of others more recently.

In this sense, then, the APA report may be viewed as a pro forma recognition of the TD problem. Confronted with the expanding knowledge of the TD epidemic and challenged by malpractice litigation, APA had to take some action. But without a stronger organizational push for (1) education about TD, (2) monitoring patients on neuroleptics, and (3) reducing dosage level or length of time on these drugs, the effect of the task force report is unclear. It is therefore striking that the APA waited six years before circulating a summary of the report to its membership.

While the APA task force did not support education to the fullest extent that it could, it is unclear what type of educational campaign would work. Crane (1977) found that average daily dosages of neuroleptics prescribed in a well-known hospital actually increased after he had given a lecture and met with physicians to emphasize the necessity of reducing medications. Crane (1977, p. 756) concluded:

The results of this survey cannot be generalized, of course. Yet, if an oral communication accompanied by a discussion of a topic of mutual interest is ineffective, I doubt very much that the medical community can be influenced by the more impersonal communications offered by the scientific literature.

Psychiatrists who are critical of the profession's lax treatment of the problem argue that if doctors were really concerned, they would reduce their use of neuroleptics and reduce dosages when drugs are employed; such reduction has not occurred when measured by the impact of a lecture (Crane 1980) or by national data on prescribing patterns (Gualtieri and Sprague 1984). The latter authors (1984, p. 347$)$ note:

A review of the history of TD demonstrates nothing as clearly as this disconcerting fact: since 1957, published guidelines, scientific articles, presentations at professional meetings, and Draconian admonitions in the Physician's Desk Reference seem to have little, if any, effect on actual physician behavior with respect to neuroleptic drugs.

In fact, it may well be that pharmaceutical firms are the most able to mount an educational effort (Cooperstock 1974; Koumjian 1981), though it is easy to understand why they would not do so. Additionally, given the large number of neuroleptics prescribed by nonpsychiatrist physicians, education would have to be directed toward that audience as well.

At the institutional level, hospitals' failure to establish monitoring systems for TD, as recommended by the APA task force, has facilitated excess drug prescription (Crane 1980). But even in a hospital which adopted the APA Task Force guidelines, clinicians initially resisted informing patients of the potential of contracting TD, though many were later willing to discuss TD with patients (Munetz 1985). Gualtieri and Sprague $(1984$, p. 346$)$ noted that those guidelines "are more honored in the breach than in the keeping."

Some of the above material suggests that ignorance is a more likely explanation than resistance; but elements of resistance have been manifested. Occasionally doctors have covered up the TD problem: In the important Rennie $v$. Klein right-to-refuse-treatment case, psychiatrists were found to have failed to record evidence of TD, to have denied the prevalence of the syndrome, and to have disciplined staff members who persisted in noting dyskinetic symptoms on patient charts. One of the hospitals under litigation had previously told accrediting officials that no patients suffered TD, but a court-ordered study found that $25 \%$ to $40 \%$ of the patients had TD (Brooks 1980).

A "mild" form of resistance is evidenced in techniques of neutralization by which psychiatrists accept TD as a risk far outweighed by the benefits of therapy. In making a riskbenefit analysis, they calculate that the risks of contracting TD and/or of actually living with TD are worth the relief from severely disabling 
psychotic symptoms. Mason and Granacher's (1980, p. 215) text on drug therapy defends present prescribing practices by arguing that many nonpsychiatric drugs have worse side effects than psychiatric compounds, yet are not subject to such intense criticism and the demand for informed consent:

When consideration is given to the hundreds of millions of doses of antipsychotics administered over decades with the very infrequent development of TD severe enough to be socially or occupationally disabling, the conclusion is inevitable that the antipsychotic agents are among the safest agents in the medical armamentarium. Even if a mild TD develops, it is not a heavy price to pay for relief from the suffering and other disabling symptoms of schizophrenia and other psychoses.

But these doctors' notion of "infrequent development of TD" is at odds with the average $26 \%$ prevalence noted by leading experts, and by the current expansion of knowledge on TD. The risk-benefit trade-off is, in this instance, a subjective judgment which is hard for the outside observer to evaluate. Yet psychiatrists' decisions to take the risk in order to gain the benefit must be seen in light of commonly recognized problems in psychopharmacology: poor knowledge base, overprescribing, and polypharmacy.

In their text, Mason and Granacher appeal to the fact that other medical practices have iatrogenic effects and that therefore psychiatry is excused from dealing more appropriately with TD. But a risk-benefit calculation is not always clear-cut. Chan et al. (1980) argue that the benefits of neuroleptics are exaggerated because about $20 \%$ of all patients have psychotic relapses more frequently on than off medications; nor is it possible to predict which patients they will be. Thus, if that percentage of patients do better without drugs, the standard risk-benefit model, when based on the assumption that all patients do better on neuroleptics, would put more of them at risk for TD.

At a more fundamental level, a risk-benefit approach is too easily used as a way of minimizing the severity of the TD epidemic. When there is a dichotomous choice between symptoms and side effects, pharmaceutical companies can avoid responsibility for underinformation; physicians, for lack of knowledge; and practitioners and institutions, for overreliance on drugs.

\section{Malpractice Litigation and Informed Consent}

It might be expected that psychiatric resistance to dealing appropriately with TD would diminish once malpractice litigation became a significant factor, yet this is not the case. Since 1978 ten lawsuits have been filed by patients and their families against institutions which provided treatment resulting in tardive dyskinesia. In the 1980 Clites $v$. Iowa case, a mentally retarded man was awarded $\$ 760,000$ in damages from the state for negligent treatment resulting in TD. In the 1982 Faigenbaum v. Oakland Medical Center case, a \$1 million award was made to a mentally ill woman who developed the syndrome. In both cases, patients and family had not been informed of the danger of developing the illness, and physicians were negligent in diagnosis and treatment (Wettstein 1984). In 1984, the Headley v. Hannekan et al. case was decided for the plaintiff entirely on the basis of failure to warn of early signs of TD. The award was $\$ 315,000$. The largest award yet, over $\$ 3$ million, was made in 1984 in Hedin and Hedin v. United States of America, based on overprescribing and lack of monitoring by a V.A. hospital (Gualtieri et al. 1985). Prior to 1979,9 of 12 out-of-court settlements resulted in amounts ranging from $\$ 1,850$ to $\$ 190,000$. Gualtieri and Sprague (1984) expect a flood of suits due to lack of change in practice. The APA believes that the lawsuits would have failed if psychiatrists had documented in medical records their monitoring for TD symptoms and their discussions of risks with patients and families. California now requires disclosure of TD (Marder et al. 1983), perhaps signalling a new trend in state mental health services. Related to this is the possibility that TD malpractice may become more likely to be determined by "strict liability" than by "community standards of professional care." The strict liability approach, already suggested in the Clites case, holds that the product or treatment is so inherently dangerous that the defendant bears a type of automatic responsibility for the detrimental out- 
come. If strict liability reasoning does prevail, it may exert even more pressure on physicians to alter their practices (Gualtieri et al. 1985).

Despite well-published court cases decided against psychiatrists and increasing awareness of a TD epidemic, psychiatrists do not, by and large, inform patients and their families adequately about the risks of TD.

Even when physicians believe that patients should be informed of the risks of TD, usually only incomplete information is given (Breggin 1983, pp. 243-44), not all patients at risk are informed. For instance, one article (Sovner et al. 1978) incorrectly held that because patients were not at high risk until they had taken neuroleptics for more than a year, there was no reason to tell patients of the risks of TD until a year of continuous drug therapy had elapsed. Jeste and Wyatt (1981), despite finding high TD prevalence rates, argue that patients and family should be told that the risk of TD cannot be estimated for any individual patient.

The APA task force opposed specific written consent, and stated that the psychiatrist should "educate" the patient in whatever manner is seen fit. APA objection to written consent derives from research knowledge that has shown that it is formalistic, deals with only a single point in time (Lidz et al. 1984), and may even be less effective than structured verbal consent (Munetz and Roth 1985). Yet the APA task force might have chosen the alternative path of involving patients in a greater amount of disclosure and treatment planning-for instance, by developing model disclosure techniques from a few actual programs.

Lidz et al.'s (1984, pp. 187-89, 277) in-depth study of informed consent found that, in the case of neuroleptics, psychiatrists informed patients about a variety of areas, such as benefits and short-term side effects (e.g., dry mouth), but not about the risk of TD. Another study found that doctors talked with patients far less often about TD and other major side effects than about other aspects of the drug regimen (Benson 1984). A study by Munetz et al. (1982) of TD in outpatients generated heated discussion among members of their hospital's research committee which centered on the fear that patients would refuse drugs if they were informed of the TD risk. Munetz et al. (1982), who systematically informed patients, were criticized by their hospital's research commit- tee for allegedly putting large numbers of seriously ill patients at risk of decompensation. Interestingly, the research committee argued that the investigators would find very few cases of "true" TD. Fear of litigation was also expressed. As the researchers write:

The notion exists that since many patients do not recognize their abnormal movements, it's best not to call the tardive dyskinesia to their attention. A similar argument is made against periodic drug withdrawal or dose reductions to improve early detection of tardive dyskinesia. It is feared that the physician who tells the patient of his tardive dyskinesia may be the physician to get sued. This "defensive medicine" may lead to poor practice such as not discussing patients' movements with them and not attempting periodic dose reductions. Paradoxically, it is argued that poor practice may protect against malpractice suits [emphasis added].

In fact, there was no difference in relapse rates for the patients who were informed and those who were not. The study did lead to one suit which was soon withdrawn. Ultimately, informed consent made no difference in patients' actual understanding of the drugs' benefits and risks. Nor was there a difference in that understanding between two experimental groups: one involving verbal consent and the other, verbal plus written consent. An unintended consequence of Munetz et al.'s (1982) study is that, because therapists wanted to avoid having their patients enter the study, they began talking more about TD to them. Similarly, clinicians became more sensitive to early detection and treatment.

Our discussion of recognition and resistance has demonstrated that various types of psychiatric resistance to TD recognition have coexisted with the growth of psychiatric understanding of the problem's severity. The next task is to examine underlying factors which might explain both the unevenness of the recognition process and the continued resistance.

\section{UNDERLYING CAUSES OF UNEVEN RECOGNITION AND OF RESISTANCE}

We may view the TD recognition process as a manifestation of both basic power differentials in the doctor-patient relationship and 
some key underpinnings of thinking and practice styles. Although TD is now perceived as a major problem, the recognition process leading to this heightened state of awareness has been uneven, flawed, and accompanied by remaining elements of resistance.

The TD problem can be understood theoretically with reference to both conflict-oriented professional dominance theory and labeling theory. Both labeling theorists (Scheff 1975) and conflict theorists (Freidson 1970) have argued that medical thinking and practice relegates patients to a subordinate position. These theorists also point to the use of professional power to further practitioners' personal interests as well as to compensate for flaws in their scientific knowledge. This section will analyze the TD data first with regard to the medical model and its view of the patient, and second with regard to professional protectionism and change.

\section{The Patient's Subordinate Status}

Patients, because they occupy an unpowerful position, are not taken seriously enough by physicians. Paulson (1975), an early observer of the TD problem, argued that TD victims were neither important nor visible. In the early years of TD research, the most affected group were state hospital patients, who received, according to Paulson, "the least intensive medical care in America." They were usually psychotic, and often did not complain of TD. In this light, it is interesting to observe that the Task Force report on TD, like most professional literature on the subject, does not address the personal suffering of the patient. No attention is paid to the debilitating effects which TD has on a person's life. This shortcoming is inappropriate in terms of patient care, and it may also hinder a patient's willingness to continue to cooperate in treatment.

The failure to notice the patient as a person is related to physician-patient differences in perception of medication efficacy: Physicians usually perceive medication in terms of symptom reduction and/or illness cure, whereas patients typically are more concerned about its effect on daily living routines (Schneider and Conrad 1983). Estroff's (1981) ethnographic study of aftercare clients revealed that despite agreement with providers on the need for psychoactive drugs, patients experienced the drugs in terms of their disabling side effects and visible stigmata, which produce barriers to social integration. That psychiatrists do not appreciate the quality and extent of such experience of treatment indicates that they are concerned with narrow medical issues rather than broader sociomedical ones. This may be an inevitable result of medical training, yet it demonstrates some important shortcomings of such training: concern with symptomatic relief at the expense of major side effects, and emphasis on individual pathology without regard for social components of the experience of illness. Inherent in much doctor-patient interaction, such a belief system is amplified by the fact that psychiatrists rely on drugs, often too heavily, and very commonly with flawed knowledge and practice in drug treatment.

\section{Professional Dominance-Professional Protection and Overreliance on Drug Treatment}

Psychiatry has drifted toward a stricter medical model, centered on pharmacological interventions. This biopsychiatric trend stems from the perceived success of psychoactive drugs, the psychiatric profession's attempt to identify more closely with the rest of the medical community by appearing more scientific, and the perception that the community mental health approaches of social activism and psychosocial treatment have shown little progress. Research funding and medical school psychiatry department restructuring have contributed to this growth of biopsychiatry (Light 1980, pp. 337-38). Although psychoactive medications have proven their usefulness in a wide range of applications, these drugs are often employed incorrectly, or in the absence of a more holistic view of mental health care.

Surveys of psychiatrists have found deficient knowledge concerning indications, physiological basis, toxicity, and side effects of various psychoactive drugs (Gottlieb et al. 1978; Waldron 1977). This lack of knowledge concerning medications is to some extent a result of physicians' obtaining much of their information about psychotropic drugs from drug manufacturers (Cooperstock 1974). Half of all doctors 
cite information provided by drug company sales representatives as their primary source of information, and $25 \%$ get their primary drug information from industry publications (Koumjian 1981).

Overmedication is a significant phenomenon in the prescription of neuroleptics. Segal et al. (1980) found that residents of sheltered-care facilities receiving neuroleptics were much more likely to be overmedicated than undermedicated $^{2}$ :

Compared with Hollister's recommended daily dosages for psychiatric outpatients (50-400 mg.), $60 \%$ of those in our study were medicated at the recommended level, $39 \%$ were above the recommended level, and only $1 \%$ were below the advised level. Compared with the American Medical Association's Drug Evaluations (30-1000 mg.), 89\% of the sample were within the recommended level, $10 \%$ were above it, and only $1 \%$ were below.

The overmedication of patients is well illustrated by studies in which antipsychotic dosage was either reduced or discontinued with no adverse, and often positive, results. Crane reduced average daily dosage levels for longterm inpatients from $336 \mathrm{mg}$ chlorpromazine (CPZ) equivalent to $134 \mathrm{mg} \mathrm{CPZ} \mathrm{equivalent}$ over a period of three years (noted in Scheff 1976). Crane also found that one third of the patients in his study were initially overmedicated by an average of $400 \mathrm{mg}$ CPZ equivalent. Elsewhere, Kurucz and Fallon (1977) demonstrated the efficacy of discontinuing phenothiazine treatment of state hospital patients who had been hospitalized for over 16 years on average. Ninety days after initiation of the hospital-wide program, $31 \%$ of 944 patients remained off medication with no deterioration in their condition. Kupers (1982) noted similar success in community mental health center outpatient care, when discontinuation of phenothiazine treatment was advocated by the primary psychiatrisi.

Is TD recognition a function of social divisions within psychiatry? Those psychiatrists who were active in the discovery of TD were associated with NIMH, medical schools, and research institutes. This is not surprising since those doctors would be far more likely than state hospital psychiatrists to have the time and resources to engage in research and critical reflection. Further, the fact that state-hospital psychiatrists carry not only a large patient load but one comprising more seriously disturbed patients may make it difficult for the former to consider the dosage reductions and extended drug-free periods which are dictated by compliance with TD precautions. Indeed, one of the key elements in recent mental health policy and practice has been the conflict between the more traditional state hospital staff and innovative professionals in other settings. A California State Assembly survey found that only $17 \%$ of public staff psychiatrists routinely discussed TD with patients, compared to $34 \%$ of private practitioners. A confounding factor was that the public doctors' patients were involuntary, and the private ones, voluntary (Benson 1984). Benson's (1984) survey of reported disclosure practice confirmed, however, that state hospital doctors were less likely to disclose TD or other side effects.

The higher degree of awareness and research agendas among non-state hospital psychiatrists does not, however, mean that biopsychiatric researchers as a group would necessarily recognize TD. On the contrary, it is because they are the leaders of psychiatry's effort to both medicalize itself and champion pharmacological cures that they might see TD as representing a threat to such endeavors. Thus, a research orientation does not necessarily lead to widespread recognition of TD. It is important to remember that early recognition of TD was the work of only a small number of psychiatrists.

Perhaps the reluctance to make the TD case into a larger public health issue stems from the fact that to take such a tack might suggest that the profession was not in control of its own practice. Were that so, one implication might then be that external regulation would be necessary, and physicians have always resisted such control. As Freidson (1970) argues, physicians place enormous emphasis on protecting their professional status. In psychiatry's case, that can be done by increasingly adhering to a psychopharmacological perspective in a period when social and community psychiatry continue their decline (Light 1980). Professional dominance also involves the minimization of the importance of errors and mistakes, particularly disclosure of them to the patient (Millman 1976). Were psychiatrists to recog- 
nize the extent of the TD problem, they would call into question much of what they conceive to be their most successful effort in treating mentally ill persons. They would have to accept the effect of this iatrogenic condition, and physicians generally do not like to accept iatrogenic results of their treatment (Paulson 1975).

In the case of iatrogenesis the physician is clearly at fault. It is not correct, however, simply to equate iatrogenesis with side effects, if what is meant by side effects is the inescapable result of appropriate and beneficial treatment. While neuroleptics are successful in most cases, there is a significant minority for whom they are not (Scheff 1976). Further, neuroleptics are overprescribed for patients for whom the drugs are indicated (Crane 1980). In addition, the frequent incorrect diagnosis of schizophrenia for persons with affective disorders places yet more patients unnecessarily at risk (Lipton and Simon 1985).

The above discussion of psychiatric thinking and practice points to a general problem in drug innovation. Jeste and Wyatt (1982b, p. 9) consider TD in light of the "law of the new drug," whereby soon after a compound is developed, it is hailed as a panacea, and few side effects are noticed. Then the pendulum swings in the opposite direction, and the opinion is widely held that the drug is toxic and has limited clinical use. For Jeste and Wyatt the truth lies between the two extremes; in a more sociological vein, Waldron (1977) characterizes new drug development in the following manner:

A pattern emerges of early claims of high efficacy and great safety based on uncontrolled studies, followed by widespread use not rationally based on scientific evidence, and finally an accumulation of evidence of serious adverse effects together with the demonstration of much lesser effectiveness in controlled studies.

McKinlay (1981) expands Waldron's model to all medical innovations, and identifies seven stages of development. Innovations first enter into awareness by way of the "promising report," in professional journals and/or mass media outlets. Such innovations lack adequate methodologies, but are usually supported by endorsements from manufacturers and/or enthusiastic researchers. The second stage of "professional and organizational adoption" involves scattered support for adoption by professional bodies and institutions. In the third stage of "public acceptance and state (thirdparty) endorsement," manufacturers, professionals, and medical organizations press for state endorsement which leads to research funding and third-party reimbursement. Interestingly, it is often only after this endorsement that the state pursues large-scale research into the drug or technique's efficacy. Regarding the fourth stage of "standard procedure," McKinlay states: "So entrenched has the activity become that it takes rare courage for any individual or group to even question its effectiveness or desirability." This is followed by the fifth stage of "randomized controlled trials," which often show innovations to be either ineffective or no more effective than traditional treatments. In response comes the stage of "professional denunciation" of the critics. Here, professional prestige plays a greater role than scientific knowledge, as leaders employ their influence in the pages of journals and in special research evaluation committees. In the final stage, "erosion and discreditation," the treatment's problems are finally recognized. Perhaps a scandal occurs, or other treatments prove to be better, or the innovation is understood to have only limited applications.

Neuroleptic treatment and TD recognition have rather closely followed these stages, with two exceptions. Professional denunciation of the critics came prior to randomized trials. Also, instead of the final stage of discreditation, there is a less than complete recognition of problems and a lack of adequate countermeasures. McKinlay cautions that all innovations do not necessarily go through each of the seven stages. He emphasizes that many innovations gain credence through weak medical research and the exercise of power by professional bodies, institutions, and drug firms. As a result, there is often a rash, impulsive move to adopt new treatments, without sufficient attention paid to their risks.

Waldron and McKinlay's approach is particularly apt in this case. Given our argument that the TD problem lies largely in psychiatry's development as a profession, it is clear that the problems of drug innovation are exacerbated in a period of transition. During the time when 
psychopharmacology was growing and was creating major alterations in psychiatry, knowledge and methods were too new for the degree of confidence providers placed on them. It is ironic that professional change created a source of recognition of TD and of resistance to its recognition. Pharmacological advances made psychiatrists overly optimistic and blind to the problems in their new techniques, but those advances also upset the traditional balances and tensions in the psychiatric profession. That provided a basis for critics within the profession to voice their concerns.

As is true in social reform in general, an active "left" wing may allow a broad "center" to take up reform issues which might otherwise be too difficult. The APA Task Force most likely represents a broad center consensus which realized the need to tackle the TD problem directly in order to minimize criticism from within and without the profession. This does not mean that all psychiatrists will adhere to the cautions suggested by the task force. Further, there will no doubt remain some critics for whom the task force recommendations are too weak. Yet the combination of the task force and of the growing recognition of the TD problem by clinicians and researchers can be considered a begrudging and belated recognition of the problem. TD is now considered a major problem, and various precautions are taken seriously, even if mainly in theory.

\section{CONCLUSION}

The preceding section has explored a number of facets of psychiatric thinking and practice which account for the belated and uneven recognition of $\mathrm{TD}$, and for resistance to recognizing the severity of the problem. Such resistance and incomplete recognition coexist with a routine process of discovery of the effects of medical technology. Those psychiatrists and their professional organizations which pursued the TD problem were very likely sincere in their efforts, yet were ultimately limited by professional socialization and institutional constraints. Further, many practicing psychiatrists and institutions were unaffected by this discovery process because of the lack of centralized policy-making for any specialty practice.

The misdirection of therapeutic efforts, we have argued, has been a result of the transformation of psychiatry in the past three decades, stemming from the ascendancy of biopsychiatry and psychopharmacology. Changing beliefs and new practice styles affected individual practitioners as well as institutions. As a result, the TD problem flourished in the context of (1) physicians' lack of knowledge concerning psychoactive drugs, (2) a general dependence on pharmacological methods, (3) a perspective that focuses on individual pathology and pharmacological cure while neglecting the social nature of mental illness, (4) a preference for keeping patients out of hospitals, and (5) efforts to maintain professional legitimacy.

The flawed discovery of tardive dyskinesia is of significance to the whole society, since the expansion of the use of psychotropic drugs affects many persons with minor psychological problems as well as those with mental illness and mental retardation (Gualtieri et al. 1985). Social control functions of these medications include work- and sex-role socialization (Waldron 1977), custodial care of nursing home patients (Ray et al. 1980), and maintenance of prisoners and juvenile delinquents (Lerman 1982). The need for quick, efficient, and costeffective solutions to the problems of mental illness is of importance only in a society where speed, efficiency, and parsimony are highly valued at the expense of humanitarian concerns. The prevention of tardive dyskinesia thus requires a reformulation of priorities, so that mental health professionals will no longer seek the "easy treatment" technique of excessive medication, and so that mental health funding will no longer make active psychosocial treatment only an infrequent experiment. In this light, it is interesting that in addition to the direct benefit of increased recognition for current and potential TD sufferers, an unintended consequence of TD recognition is also evident: as the authors of the APA Task Force (Baldessarini et al. 1979, p. 17) report, the TD problem has led to a general questioning of the benefits and risks of psychotropic drug treatment.

It may be argued that the process of "discovering" TD was quick, relative to recogni- 
tion of other medical errors and damaging side effects. An extension of this argument might be that the psychiatric profession acted in a responsible fashion (if we take the profession to be largely represented by the APA and its TD Task Force, and by leading experts involved in recent TD recognition). Even so, we have traced here a history of disease discovery and learned that it does not follow a simple line of increased medical knowledge, but rather involves a variety of larger sociomedical factors. Thus, without blaming psychiatrists individually or collectively, we can understand the professional constraints against recognition of the problem. This is particularly important when we take into account the dilemma of neuroleptic compounds: They promise some benefits to psychotic patients, yet involve serious iatrogenic suffering.

The discovery of tardive dyskinesia offers important lessons in the sociological recognition of disease. We become more aware that disease is not discovered solely through the advance of medical science, and that social factors may hinder such discovery. Professional self-interest may also play a role in preserving a problematic treatment form. As a result, inappropriate or partial solutions may be offered, and public pressures may be necessary to overcome the obstacles which professionals erect. This pressure may emerge through victims and/or their allies, or by a more diffuse social pressure brought about through increased visibility of the condition. Sometimes advances are made from within the psychiatric profession, since it is by no means monolithic in its practices. Nevertheless, monitoring by forces external to the health care delivery system may be necessary to insure effective and equitable solutions.

\section{NOTES}

1. Neuroleptics (often referred to as major tranquilizers, ataraxics, or antipsychotics) include the following drug classifications: phenothiazines, butyrophenones, thioxanthenes, dibenzazepines, diphenylbutylpiperidines, indolones, and rauwolfia.

2. Dosage levels are given in chlorpromazine (CPZ) equivalents, or the amount of chlorpromazine necessary to produce the same effect of another phenothiazine derivative.

\section{REFERENCES}

Baldessarini, Ross J., Jonathan O. Cole, John M.
Davis, George Gardos, Sheldon H. Preskorn, George M. Simpson, and Daniel Tarsy. 1979. Tardive Dyskinesia: Report of the American Psychiatric Association Task Force on Late Neurological Effects of Antipsychotic Drugs. Washington, DC: American Psychiatric Association.

Benson, Paul R. 1984. "Informed Consent: Drug Information Disclosed to Patients Prescribed Antipsychotic Medication." Journal of Nervous and Mental Disease 172:642-53.

Breggin, Peter R. 1983. Psychiatric Drugs: Hazards to the Brain. New York: Springer.

Brooks, Alexander D. 1980. "The Constitutional Right to Refuse Antipsychotic Medications." Bulletin of the American Academy of Psychiatry and Law 8:179-221.

Brown, Phil. 1985. Psychiatric Deinstitutionalization and Its Aftermath. London: Routledge and Kegan Paul.

Chan, H. Caryle, John M. Davis, Robert C. Smith, and Ken Reed. 1980. "Maintenance Antipsychiatric Therapy and Risks of Tardive Dyskinesia." Pp. 511-22 in Tardive Dyskinesia: Research and Treatment, edited by W.E. Fann, R.C. Smith, J.M. Davis, and Edward F. Domino. New York: Spectrum.

Cole, Jonathan O. 1974. "Discussion of Dr. Crane's Paper." Transactions of the New York Academy of Science, Series II. 36:658-62.

Cooperstock, Ruth. 1974. "Some Factors Involved in the Increased Prescribing of Psychotropic Drugs." Pp. 21-34 in Social Aspects of the Medical Use of Psychotropic Drugs, edited by Ruth Cooperstock. Toronto: Addiction Research Foundation.

Crane, George E. 1974. "Two Decades of Psychopharmacology and Community Mental Health: Old and New Problems of the Schizophrenic Patient." Transactions of the New York Academy of Science, Series II. 36:644-57.

- 1977. "The Prevention of Tardive Dyskinesia." American Journal of Psychiatry 134:756-58.

1980. "Preface" in Tardive Dyskinesia: Research and Treatment, edited by William E. Fann, Robert C. Smith, John M. Davis, and Edward F. Domino. New York: Spectrum.

Crane, George E., and George Paulson. 1967. "Involuntary Movements in a Sample of Chronic Mental Patients and Their Relation to the Treatment with Neuroleptics." International Journal of Neuropsychiatry 3:286-91.

Curran, John P. 1973. "Tardive Dyskinesia: Side Effect or Not?" American Journal of Psychiatry 130:406-10.

Diamond, Ronald. 1985. "Drugs and the Quality of Life: The Patient's Point of View." Journal of Clinical Psychiatry 46:29-35.

Estroff, Sue E. 1981. Making It Crazy: An Ethnography of Psychiatric Clients in an American Community. Berkeley: University of California Press.

Fann, William E., John M. Davis, and David S. 
Janowsky. 1972. "The Prevalence of Tardive Dyskinesia in Mental Hospital Patients." Diseases of the Nervous System 33:182-86.

Fann, William E., John Stafford, Russell L. Malone, James D. Frost, Jr., and Bruce W. Richman. 1977. "Clinical Research Techniques in Tardive Dyskinesia." American Journal of Psychiatry 134:759-62.

Freidson, Eliot. 1970. Profession of Medicine. New York: Dodd, Mead.

Gardos, George, and Jonathan O. Cole. 1980. "Problems in the Assessment of Tardive Dyskinesia." Pp. 201-14 in Tardive Dyskinesia: Research and Treatment, edited by William E. Fann, Robert C. Smith, John M. Davis, and Edwzrd F. Domino. New York: Spectrum.

Gibson, Alan C. 1978. "Depot Injections and Tardive Dyskinesia." British Journal of Psychiatry 132: 361-65.

Glick, Burton S., and Reuben Margolis. 1962. "A Study of the Influence of Experimental Design on Clinical Outcome in Drug Research." American Journal of Psychiatry 118:1087-94.

Goode, William J. 1960. "Encroachment, Charlatanism, and the Emerging Profession: Psychology, Sociology, and Medicine." American Sociological Review 25:902-14.

Gottlieb, Richard M., Theodore Nappi, and James J. Strain. 1978. "The Physician's Knowledge of Psychotropic Drugs: Preliminary Results." American Journal of Psychiatry 135:29-32.

Gualtieri, C. Thomas, and Robert L. Sprague. 1984. "Preventing Tardive Dyskinesia and Preventing Tardive Dyskinesia Legislation." Psychopharmacology Bulletin 20:346-48.

Gualtieri, C. Thomas, Robert L. Sprague, and Jonathan O. Cole. 1985. "Tardive Dyskinesia Litigation and the Dilemmas of Neuroleptic Treatment." Unpublished manuscript.

Jeste, Dilip V., and Richard J. Wyatt. 1981. "Changing Epidemiology of Tardive Dyskinesia: An Overview." American Journal of Psychiatry 138:297-309.

1982a. "Therapeutic Strategies Against Tardive Dyskinesia." Archives of General Psychiatry 39:803-16.

1982b. Understanding and Treating Tardive Dyskinesia. New York: Guilford.

Kane, John M., and James M. Smith. 1982. "Tardive Dyskinesia: Prevalence and Risk Factors, 1959 to 1979." Archives of General Psychiatry 37:473-81.

Klerman, Gerald. 1982. "The Psychiatric Revolution of the Past Twenty-Five Years," in Deviance and Mental Illness, edited by Walter Gove. Beverly Hills, CA: Sage Publications.

Kline, Nathan S. 1968. "On the Rarity of "Irreversible' Oral Dyskinesias Following Phenothiazines." American Journal of Psychiatry 124:48-54.

Koumjian, Kevin. 1981. "The Use of Valium as a Form of Social Control." Social Science and Medicine 15E:245-49.

Kupers, Terry. 1983. Public Psychiatry. New York: Free Press.

Kurucz, Janos, and John Fallon. 1980. "Dose Re- duction and Antipsychotic Medication." Hospital and Community Psychiatry 31:117-18.

Lennard, Henry, and Arnold Bernstein. 1974. "Perspectives on the New Psychoactive Drug Technology." Pp. 149-65 in Social Aspects of the Medical Use of Psychotropic Drugs, edited by Ruth Cooperstock. Toronto: Addiction Research Foundation.

Lerman, Paul. 1982. Deinstitutionalization and the Welfare State. New Brunswick, NJ: Rutgers University Press.

Lidz, Charles W., Alan Meisel, Eviatar Zerubavel, Mary Carter, Regina M. Sestak, and Loren H. Roth. 1984. Informed Consent: A Study of Decisionmaking in Psychiatry. New York: Guilford.

Light, Donald. 1980. Becoming Psychiatrists: The Professional Transformation of Self. New York: Norton.

Lipton, Alan A., and Franklin S. Simon. 1985. "Psychiatric Diagnosis in a State Hospital: Manhattan State Revisited." Hospital and Community Psychiatry 36:368-73.

Marder, Stephen R., Andrew Mebane, Ching-piao Chien, William Winslade, Elizabeth Swann, and Theodore Van Putten. 1983. "A Comparison of Patients Who Refuse and Consent to Neuroleptic Treatment." American Journal of Psychiatry 140:470-72.

Mason, Aaron S., and Robert P. Granacher. Clinical Handbook of Antipsychotic Drug Therapy. New York: Brunner/Mazel.

McKinlay, John B. 1981. "From 'Promising Report' to 'Standard Procedure': Seven Stages in the Career of a Medical Innovation." Milbank Memorial Fund Quarterly/Health and Society 59:374 411.

Millman, Marcia. 1976. The Unkindest Cut: Life in the Backrooms of Medicine. New York: Morrow.

Mishler, Elliot G., Lorna R. Amarasingham, Stuart T. Hauser, Ramsay Liem, Samuel D. Osherson, and Nancy E. Waxler. 1981. Social Contexts of Health, Illness, and Patient Care. Cambridge: Cambridge University Press.

Munetz, Mark R. 1985. "Overcoming Resistance to Talking to Patients About Tardive Dyskinesia." Hospital and Community Psychiatry 36:283-87.

Munetz, Mark R., and Loren H. Roth. 1985. "Informing Patients About Tardive Dyskinesia." Archives of General Psychiatry 42:866-71.

Munetz, Mark R., Loren H. Roth, and Cleon L. Cornes. 1982. "Tardive Dyskinesia and Informed Consent: Myths and Realities." American Academy of Psychiatry and Law Bulletin 10:77-88.

National Institute of Mental Health. 1983. "Number of Resident Patients, Total Admissions, Net Releases, and Deaths, State and County Mental Hospitals: United States, 1950-1980." Unpublished data.

Parsons, Talcott. 1959. "Some Problems Confronting Sociology as a Profession." American Sociological Review 24:547-52.

Paulson, George W. 1975. 'Tardive Dyskinesia.' Annual Review of Medicine 26:75-80. 
Prien, Robert F., and Jerome Levine. 1984. "Research and Methodological Issues for Evaluating the Therapeutic Effectiveness of Antidepressant Drugs." Psychopharmacology Bulletin 20:250-57.

Quitkin, Frederic A., Arthur Rifkin, Linda Gochfeld, and Donald F. Klein. 1977. "Tardive Dyskinesia: Are First Signs Reversible?" American Journal of Psychiatry 134:84-87.

Ray, Wayne A., Charles Federspiel, and William Schaffner. 1980. "A Study of Antipsychotic Drug Use in Nursing Homes: Epidemiologic Evidence Suggesting Misuse." American Journal of Public Health 70:485-91.

Scheff, Thomas. 1975. Labeling Madness. Englewood Cliffs, NJ: Prentice-Hall.

- 1976. "Medical Dominance: Psychiatric Drugs and Mental Health Policy," American Behavioral Scientist 19:299-316.

Schiele, Burtrum C., Donald Gallant, George Simpson, Elmer A. Gardner, and Jonathan O. Cole. 1973. "Tardive Dyskinesia: A Persistent Neurological Syndrome Associated with Antipsychotic Drug Use." Annals of Internal Medicine 79:99-100.

Schmidt, William R., and Leonard W. Jarcho. 1966. "Persistent Dyskinesias Following Phenothiazine Therapy." Archives of Neurology 14 (April):369-77.

Schneider, Joseph, and Peter Conrad. 1983. Having Epilepsy: The Experience and Control of Illness. Philadelphia: Temple.

Segal, Steven P., Susan Chandler, and Uri Aviram. 1980. "Antipsychotic Drugs in Community-Based Sheltered-Care Homes." Social Science and Medicine 14A:589-96.
Simpson, George, and Nathan S. Kline. 1976. "Tardive Dyskinesia: Manifestations, Incidence, Etiology, and Treatment" in The Basal Ganglia, edited by Melvin D. Yahr. New York: Raven Press.

Smith, M., L. Kucharski, C. Eblen, E. Knutsen, and C. Linn. 1979. "An Assessment of Tardive Dyskinesia in Schizophrenic Outpatients." Psychopharmacology 64:99-104.

Sovner, Robert, Alberto DiMascio, David Berkowitz, and Peter Randolph. 1978. "Tardive Dyskinesia and Informed Consent." Psychosomatics 19:172-77.

Sprague, Robert L., David M. White, Rina Ullman, and John E. Kalachnik. 1984. "Methods for Selecting Items in a Tardive Dyskinesia Rating Scale." Psychopharmacology Bulletin 20:339-45.

Swazey, Judith P. 1974. Chlorpromazine in Psychiatry: A Study of Therapeutic Innovation. Cambridge: MIT Press.

Turek, Ibrahim, Albert A. Kurland, Thomas E. Hanlon, and Mark Bohm. 1972. "Tardive Dyskinesia: Its Relation to Neuroleptic and Antiparkinson Drugs." British Journal of Psychiatry 121:605-12.

Waldron, Ingrid. 1977. "Increased Prescribing of Valium, Librium, and Other Drugs: An Example of the Influence of Economic and Social Factors on the Practice of Medicine." International Journal of Health Services 7:37-61.

Wettstein, Robert M. 1984. "Legal Liability for Tardive Dyskinesia." Hospital and Community Psychiatry 35:992-94.

Zola, Irving K. 1983. Socio-Medical Inquiries. Philadelphia: Temple University Press.

\section{MANUSCRIPTS FOR THE ASA ROSE SOCIOLOGY SERIES}

Manuscripts (100 to 300 typed pages) are solicited for publication in the ASA Arnold and Caroline Rose Monograph Series. The Series welcomes a variety of types of sociological workqualitative or quantitative empirical studies, and theoretical or methodological treatises. An author should submit three copies of a manuscript for consideration to the Series Editor, Professor Ernest Q. Campbell, Department of Sociology, Vanderbilt University, Nashville, TN 37235. 